\title{
Pathologists and gastroenterologists
}

\section{Y Niv}

\section{Are they using the same language?}

$\mathrm{H}$ istopathology is the study of the cytological and histological structure of normal or diseased tissue. It is the most extensive field in medicine, serving almost all the other disciplines. The identification and quantification of tissue features has major implications for clinical diagnosis, management, and follow up, ${ }^{1}$ making evidence based cellular pathology one of the pillars of evidence based medicine. As the gold standard for diagnosis, histopathological findings must be accurate, reliable and reproducible, and the language must facilitate clear, direct communication among pathologists themselves and between pathologists and clinicians. This issue is particularly important in malignant disease, for proper evaluation, diagnosis, and management. ${ }^{2-5}$ This may be a particular problem in different countries and cultures. For example, two studies have reported a wide variation between Japanese and Western pathologists in the diagnosis of gastric cancer, ${ }^{67}$ particularly high grade dysplasia and invasive tumours.

"The identification and
quantification of tissue features
has major implications for clinical
diagnosis, management, and
follow up, making evidence based
cellular pathology one of the
pillars of evidence based
medicine"

In gastroenterology, the most common clinical decisions based on pathological findings involve the differentiation of malignant from benign lesions, characterisation of inflammation (for example, ulcerative colitis, Crohn's disease, or Helicobacter pylori gastritis), and identification of organ rejection or graft versus host disease. For example, a gastric polyp may be benign or neoplastic (adenomatous polyp or early gastric cancer or mucosa associated with lymphoma), ${ }^{8}$ as may a colonic polyp (adenoma with or without villous component, with or without high grade dysplasia, or invasive cancer). ${ }^{9}$ Histopathological study of a biopsy from the terminal ileum can differentiate Crohn's ileitis from tuberculosis, ${ }^{10}$ and the study of a colonic biopsy can differentiate ulcerative colitis from specific, self limited colitis, or Crohn's disease. ${ }^{11}{ }^{12}$
In general, good tissue diagnosis is based on three procedures: sampling (biopsy), morphological evaluation, and reporting.

\section{SAMPLING}

It is the responsibility of the endoscopist to supply appropriate samples of both solid and tubular organs. In liver biopsy, accuracy can be increased with more needle passes and more samples. ${ }^{13}$ One study found that increasing the number of biopsy samples from two to eight improved the detection of oesophageal carcinoma from $95.8 \%$ to $100 \%$, meaning that four cases out of 100 are missed if only two biopsy samples are taken. ${ }^{14}$ Surveys of colorectal operations yielded a wide range (from none to 24) in the number of lymph nodes harvested by different surgeons. ${ }^{15} 16$

\section{MORPHOLOGICAL EVALUATION}

Pathologists should examine and describe only features that are both relevant to the clinician and reproducible. Efforts should be directed at lowering interobserver and intraobserver differences to a minimum. Dedicated pathologists who process the gastrointestinal samples must participate in professional meetings and symposiums, and keep abreast of new developments reported in accredited medical journals in the field. They must be well versed in the common terminology and follow accepted guidelines, such as the Sidney classification of gastritis, ${ }^{17}$ and low grade versus high grade dysplasia in Barrett's oesophagus ${ }^{18}$ and ulcerative colitis. ${ }^{19}$

\section{REPORTING}

The pathologist must accurately communicate the result and provide all the necessary data so that the gastroenterologist can make the diagnosis and take the necessary steps or, in some cases, recognise any unknowns or uncertainties. Bull et al found that up to $50 \%$ of pathologists' reports failed to provide all the accepted data needed for colorectal cancer staging..$^{20}$ In another study, the use of checklists was found to increase the contents of pathology reports on colorectal cancer findings to acceptable levels. ${ }^{21}$ Pathologists must be made aware that such terms as "consistent with" or "suggestive of" can be interpreted differently by different people. ${ }^{22}$ According to one study, understanding may be increased with the use of a scoring system. ${ }^{23}$ Ignoring a specific query of the clinician can lead to confusion. For example, an "inflammatory polyp" should not be diagnosed as "colitis", "intestinal metaplasia in Barrett's oesophagus" as "normal small bowel", "low and high grade dysplasia" as "mild, moderate, or severe dysplasia" (descriptive terms that have no clinical application). Polyps should be localised and graded according to the villous component and amount of dysplasia.

The pathologist's diagnosis can dictate a change in patient management, follow up, and treatment. For example, a diagnosis of Barrett's oesophagus (Alcian blue positive intestinal metaplasia) warrants annual or biennial endoscopy and biopsy, and treatment with high dose proton pump inhibitors. ${ }^{18}$ When the diagnosis is low grade dysplasia, the next endoscopy can wait six months, but when the diagnosis is high grade dysplasia, endoscopic mucosal resection or surgery is needed..$^{18}$ A diagnosis of coeliac disease on duodenal biopsy confines the patient to a life long, gluten free diet, ${ }^{24}$ whereas Giardia lamblia infestation is treatable with short term metronidazole. ${ }^{25}$ Findings of a premalignant state of dysplasia associated with a lesion or mass in patients with long standing ulcerative colitis mandate total colectomy. ${ }^{19}$ Burroughs and colleagues found "best practice reporting" in only $20 \%$ of gastric and $18 \%$ of oesophageal cancer reports. ${ }^{26}$ A poor interdisciplinary dialogue can lead to mistreatment or mismanagement, sometimes with dire outcome.

In summary, for optimal communication between pathologists and gastroenterologists, pathologists must ensure accurate assessment and clear and relevant reportage, and the gastroenterologist must ensure proper and adequate sampling. The use of standard guidelines in both fields will support evidence based medicine, for the ultimate benefit of the patient.

J Clin Pathol 2003;56:241-242

\section{Authors' affiliations}

Y Niv, Department of Gastroenterology, Rabin Medical Center, Beilinson Campus, Tel Aviv University, Israel

Correspondence to: Professor Y Niv, Department of Gastroenterology, Rabin Medical Center, Beilinson Campus, Petach Tikva 49100, Israel; yniv@clalit.org.i

\section{REFERENCES}

1 Fleming KA. Evidenced-based cellular pathology. Lancet 2002;359: 1 149-50.

2 Mathers ME, Shrimankar J, Scott DJ, et al. The use of a standard proforma in breast 
cancer reporting. I Clin Pathol

2001;54:809-11.

3 Wilson E, Feakins R. The use of a standard proforma in breast cancer reporting. J Clin Pathol 2002:55:719.

4 Milroy CJ, Richman PI, Wilson GD, Sanders R. Reporting basal cell carcinoma: a survey of the attitudes of histopathologists. J Clin Pathol 1999;52:867-9

5 Reid WA, Al-Nafussi Al, Rebello G, et al. Effect of using templates on the information included in histopathology reports on specimens of uterine cervix taken by loop excision of the transformation zone. J Clin Pathol 1999:52:825-8.

6 Schlemper RJ, Kato Y, Stolte M. Review of histological classification of gastrointestinal epithelial neoplasia: differences in diagnosis of early carcinoma between Japanese and Western pathologists. J Gastroenterol 2001;36:445-56.

7 Schlemper RJ, Itabashi M, Kato Y, et al. Differences in diagnostic criteria for gastric carcinoma between Japanese and Western pathologists. Lancet 1997:349:1725-9.

8 Koh TJ, Wang TC. Tumors of the stomach. In Sleisenger and Fordtran's gastrointestinal and liver disease, 7th ed. Philadelphia: Saunders, 2002:829-55.

9 O'Brien MJ, Winawer SJ, Zauber AG. The national polyp study: patient and polyp characteristics associated with high-grade dysplasia in colorectal adenomas. Gastroenterology 1990;98:371-5.
10 Sands BE. Crohn's disease. In: Sleisenger and Fordtran's gastrointestinal and liver disease, 7th ed. Philadelphia: Saunders, 2002:2005-38

11 Surawicz CM, Belic L. Rectal biopsy helps to distinguish acute self-limited colitis from idiopathic inflammatory bowel disease. Gastroenterology 1984;86:104-9.

12 Dube AK, Cross SS, Lobo AJ. Audit of the histopathological diagnosis of non-neoplastic colorectal biopsies: achievable standards for the diagnosis of inflammatory bowel disease. J Clin Pathol 1998;51:378-81.

13 Olsson R, Hagerstrand I, Broome U, et al. Sampling variability of percutaneous liver biopsy in primary sclerosing cholangitis. J Clin Pathol 1995;48:933-5.

14 Lal N, Bhasin DK, Malik AK, et al. Optimal number of biopsy specimens in the diagnosis of carcinoma of the esophagus. Gut 1992;33:724-6.

15 Maniprize KS, Hewavisinthe J, Savage A, et al. How many lymph nodes to stage colorectal carcinoma? J Clin Pathol 1998:51:165-6.

16 Blenkinsopp WK, Stewart-Brown S, Blesovsky $\mathrm{L}$, et al. Histopathology reporting in large bowel cancer. J Clin Patho 1981;34:509-13

17 Misiewicz J. The Sidney system: a new classification of gastritis. J Gastroenterol Hepatol 1991;6:207-9.

18 Kahrilas PJ, Pandolfino JE. Gastroesophageal reflux disease and its complications, including Barrett's metaplasia. In: Sleisenger and
Fordtran's gastrointestinal and liver disease, 7th ed. Philadelphia: Saunders, 2002:599-622.

19 Jewell DP. Ulcerative colitis. In: Sleisenger and Fordtran's gastrointestinal and liver disease, 7th ed. Philadelphia: Saunders, 2002;2039-67.

20 Bull AD, Biffin AH, Mella J, et al. Colorectal cancer pathology reporting: a regional audit. J Clin Pathol 1997;50:138-42.

21 Shepherd NA, Ouirke P. Colorectal cancer reporting: are we failing the patient? J Clin Pathol 1997:50:266-7.

22 Attanoos RL, Bull AD, Douglas-Jones AG, et al. Phraseology in pathology reports. A comparative study of interpretation among pathologists and surgeons. J Clin Pathol 1996;49:79-81

23 Schwartz WB, Wolfe HJ, Pauker SG Pathology and probabilities: a new approach to interpreting and reporting biopies. N Engl Med 1981;305:917-23.

24 Farrell RJ, Kelly CP. Celiac sprue and refractory sprue. In: Sleisenger and Fordtran's gastrointestinal and liver disease, 7th ed. Philadelphia: Saunders, 2002:1817-41.

25 Oberhuber G, Kastner N, Stolte M. Giardiasis: a histologic analysis of 567 cases Scand J Gastroenterol 1997;32:48-51.

26 Burroughs SH, Biffin AHB, Pye JK, et al. Oesophageal and gastric cancer pathology reporting: a regional audit. J Clin Pathol $1999 ; 52: 435-9$

\section{New JCP online submission and review system}

We are pleased to inform authors and reviewers of the new online submission and review system at JCP. Developed by HighWire Press (CA, USA), Bench Press is a fully integrated electronic system that utilises the web to allow rapid and efficient submission of manuscripts. It also allows the peer review process to be conducted entirely online. We are one of the first journals in the BM Special Journals group to go online in this way. The aim, apart from saving trees, is to speed up the often frustratingly slow process (for both authors and editors) from submission to publication. Many reviewers might appreciate this too. Authors may submit their manuscript in any standard word processing software. Acceptable standard graphic formats include: jpeg, tiff, gif, and eps. The text and graphic files are automatically converted to PDF for ease of distribution and reviewing purposes. Authors are asked to approve their submission before it formally enters the reviewing process. On approval by the authors, the submission is passed to the editor and/or reviewers via the web. All transactions are secure.

To access the system click on "SUBMIT YOUR MANUSCRIPT HERE" on the JCP homepage: HYPERLINK http://www.jclinpath.com, or you can access Bench Press directly at HYPERLINK http://submit-jcp.bmijournals.com.

We are very excited with this new development and would encourage authors and reviewers to use the online system whenever possible. As editors, we will use it all the time, the up side being lack of need to travel to the editorial office to deal with papers, the down side having no more excuses to postpone decisions on papers because we are "at a meeting"!

The system is very easy to use and should be a big improvement on the current peer review process. Full instructions can be found on Bench Press http://submit-jcp.bmijournals.com and JCP online at http://www.jclinpath.com. Please contact Natalie Davies, Project Manager, HYPERLINK mailto:ndavies@bmigroup.com for any further information. 